\title{
AN APPARATUS FOR PRODUCING ARTIFICIAL TIDES
}

\author{
By Anwar Abdel Aleem, M.Sc., Ph.D. \\ (Farouk University, Alexandria) \\ From the Plymouth Laboratory
}

(Text-figs. I-2)

It is often desired to grow animals and plants of the intertidal zone in the laboratory, under conditions as far as possible simulating those in nature and with the least trouble and expense. This need was felt by the writer during an ecological study of the diatoms inhabiting the mud-flats at Whitstable, Kent. It was found necessary to maintain such diatoms in the laboratory in London in a healthy condition for several days so as to study the effect of light and tides on their movements. The apparatus described in this paper was therefore devised. It has an advantage over other tidal systems (Bracher, 1919; Martin \& Reid, 1935) in that the substratum could be automatically alternately flooded and drained at regular intervals by a much simpler mechanism. Besides, it is more handy and can be operated with only a small supply of sea water, a matter of some importance in localities remote from the sea.

It consists of a tidal chamber, $T$, and a reservoir, $R$ (Fig. I). The former is an inverted bell-jar fitted with a rubber bung through which passes a long glass tube, $g$, which extends to the base of the reservoir. At the upper end of the tube is a small funnel by which sea water enters the apparatus. A T-tube, $t$, serves to connect the tidal chamber and reservoir, its horizontal arm being connected to the siphon $S$.

The wide-mouthed bottle constituting the reservoir is fitted with a stopcock, $v$, which is useful for expelling air when setting up the apparatus.

The mud with the diatoms, $m$, is held in a container, $w$, of fine-meshed wire gauze covered with a few layers of muslin to prevent the mud from slipping through. The tube, $g$, passes through the centre of this container which rests on supports so that the upper surface of the mud is at a level about half-way up the bell-jar. The chamber $T$ can be covered with a sheet of glass, and fitted with a thermometer, but this must of course not make an air-tight fit.

When in use, sea water is allowed to drip into the funnel from the jet of the constant delivery device shown in Fig. 2. This ensures that the rate of delivery shall be the same irrespective of the level of the water in the aspirator since the pressure head remains constant, being determined only by the height, $x$ (Fig. 2). Any air-bubbles remaining after the reservoir has been filled are 
allowed to escape through the stopcock, $v$, which is then closed. The water now passes up the tube, $t$, simultaneously in the tidal chamber and the siphon-tube. When it reaches and covers the surface of the mud in the chamber a condition somewhat comparable with that of high tide is realized and persists until the water reaches the level $l$. The siphon then commences to discharge water from the tidal chamber much more rapidly than it flows in and this continues until the chamber and siphon are emptied. Water then rises again in the tidal chamber

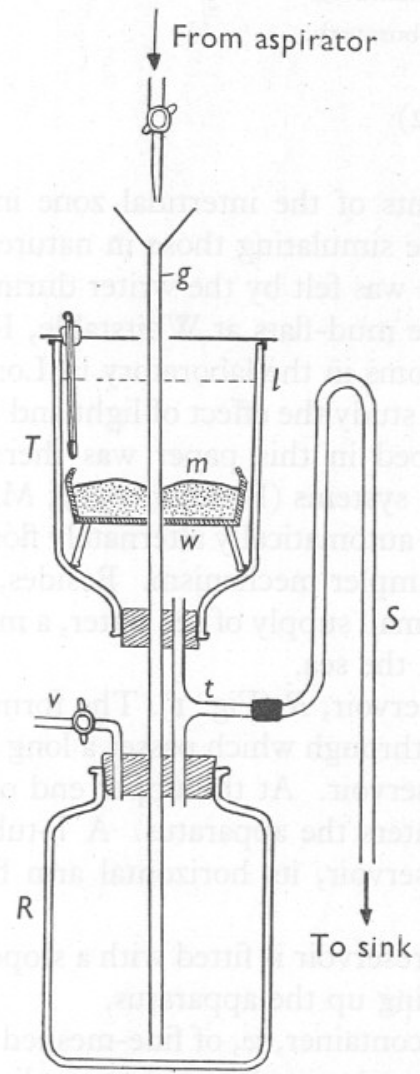

Fig. I. Tidal apparatus (for description see text).

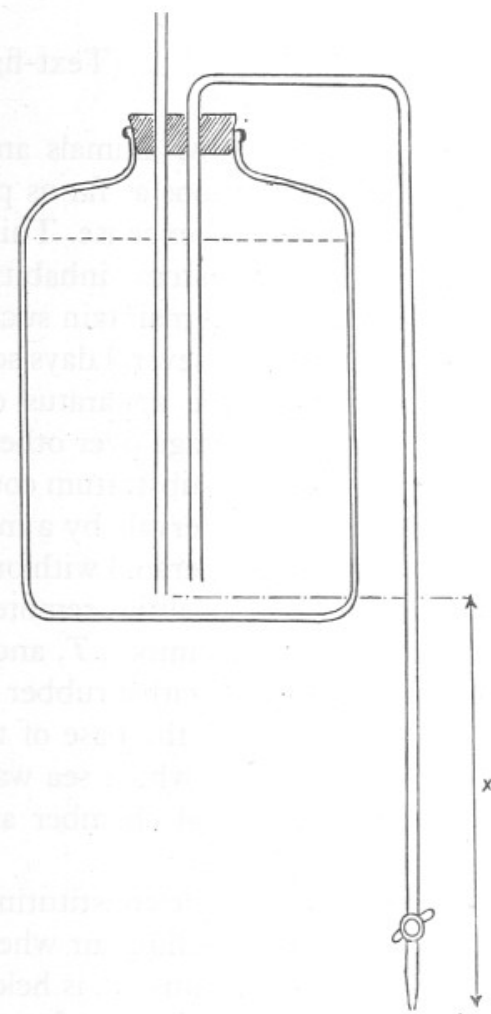

Fig. 2. Aspirator supplying the apparatus with a constant flow of sea water.

and the same succession of events is repeated. This will go on automatically for an indefinite period.

The rate of dripping, the position of the wire container holding the mud, the height of the level $l$, and the rate of discharge through the siphon can all be adjusted so that the mud surface is subjected to two periods of submergence and two periods of exposure in each $24 \mathrm{hr}$., with an interval of $6 \mathrm{hr}$. between successive phases. The bore of the siphon-tube is such that the discharge of 
water from the chamber occupies only a minute or so. The rate of supply can be adjusted by means of a tap so that longer or shorter periods of exposure or submergence of the mud can be obtained. Moreover, the effects of different factors on the movements of the diatom community can be compared by using several similar pieces of apparatus fed from a common supply of sea water.

The apparatus could be used for maintaining animals and plants of the intertidal zone in the laboratory or for studying the effects of exposure on the growth of algal germlings (Fucus, Laminaria, etc.). The mud would then be replaced by an appropriate substratum.

\section{REFERENCES}

Bracher, R., I9I9. Observations on Euglena deses. Ann. Bot., Vol. xxxvII, pp. 93-I08. Martin, M. T. \& ReID, D. M., I935. A tidal aquarium system. Fourn. Roy. Micr. Soc., Vol. LV, pp. 245-8. 